\title{
Effective control of an acute gastroenteritis outbreak due to norovirus infection in a hospital ward in Athens, Greece, April 2011
}

S P Georgiadou (sgeorg@med.uth.gr) ${ }^{1}$, D Loukeris¹, S Smilakou², G L Daikos³ , N V Sipsas ${ }^{1}$

1. Infectious Diseases Unit, Pathophysiology Department, Laikon General Hospital and Medical School, National and Kapodistrian University of Athens, Athens, Greece

2. Department of Microbiology, Laikon General Hospital, Athens, Greece

3. First Department of Propaedeutic Medicine, Laikon General Hospital and Medical School, National and Kapodistrian University of Athens, Athens, Greece

Georgiadou SP, Loukeris D, Smilakou S, Daikos GL, Sipsas NV. Effective control of an acute gastroenteritis outbreak due to norovirus infection in a hospital ward in Athens, Greece, April 2011.

Euro Surveill. 2011;16(28):pii=19915. Available online: http://www.eurosurveillance.org/ViewArticle.aspx?Articleld=19915

In April 2011, an acute gastroenteritis outbreak due to norovirus infection occurred in a hospital ward in Athens, Greece, affecting 28 people: 16 staff members, 10 inpatients and two relatives of symptomatic inpatients. The attack rate among the patients and staff was $16.4 \%(10 / 61)$ and $31.4 \%(16 / 51)$, respectively. The outbreak lasted eight days and the clinical symptoms were mild. Effective infection control measures prevented the spread of the virus to other hospital wards.

\section{Outbreak description}

Between 9 and 16 April 2011, a total of 28 cases of acute gastroenteritis occurred in an internal medicine ward of the Laikon General Hospital, in Athens, Greece. On 13 April, the Hellenic Center for Disease Control and Prevention was notified of the outbreak. Following an outbreak investigation set up by the hospital's Infection Prevention and Control committee, norovirus was found to be the causative agent of the outbreak.

Norovirus is highly contagious and important causative agent of epidemic gastroenteritis [1]. Outbreaks have been reported worldwide in diverse settings, including nursing homes, long-term care facilities and hospitals, as well as cruise ships, airplanes, military establishments and schools [2-6]. Unfortunately, infectious diseases are generally under-documented in Greece $[7,8]$. The only reported outbreak of confirmed norovirus infection in the country that we are aware of was in the town of Xanthi in 2005, in which 705 people were affected, due to waterborne transmission of the virus [9]. To our knowledge, the outbreak presented here is the first reported outbreak of norovirus infection in a Greek hospital.

\section{Setting}

Laikon General Hospital is a 487-bed, tertiary care university hospital. The 45 -bed Internal Medicine Ward, located on the fourth floor, contained nine four-bed, two three-bed, one two-bed and one onebed hospital rooms. The ward staff comprised 51 staff members: 32 doctors (of whom 21 were trainee doctors), 13 nurses and six technical staff (cleaning and food-serving staff).

\section{Epidemiological investigation}

We collected epidemiological information on all inpatients and hospital employees who had been present in the department from 9 to 23 April 2011. We interviewed both groups on a daily basis to determine the date of symptom onset and variety and duration of symptoms. Detailed history was also taken concerning any hospital food that both groups had consumed. An infection control nurse made daily rounds throughout the hospital to look for similar cases in other departments, to assess whether the outbreak was likely to be due to contaminated food or water.

An outbreak case was defined as any inpatient or employee of the internal medicine ward, or relatives who visited inpatients (from 9 to 23 April 2011), with two or more episodes of vomiting and/or diarrhoea from 9 to 23 April, with or without other symptoms and with or without laboratory confirmation.

Between 9 and 16 April 2011, a total of 28 affected people were found to meet the case definition (Figure). The mean age of the cases was 51.6 years (range: $30-88$ ) and half were male.

The main symptoms of cases were diarrhoea $(n=21)$, abdominal pain $(n=16)$, nausea $(n=15)$, vomiting $(n=13)$ and fever $\left(38.0-38.5^{\circ} \mathrm{C}\right)(\mathrm{n}=11)$. The duration of illness ranged from 10 hours to three days, with a median of 35 hours.

The index case was found to be a 70-year-old male inpatient with an underlying condition, who had been 
admitted on 7 April 2011 for other reasons. On 9 April, he reported multiple diarrhoeic episodes. Unfortunately, faecal specimens were not collected at that time. Two days later, all three male patients who had been hospitalised in the same four-bed room became symptomatic, as did another male patient who had been hospitalised in a different room. The following day (12 April), a female patient in a different room of the same ward and a trainee doctor also became symptomatic. Subsequently, the majority of the reported cases were members of the ward staff. The outbreak lasted eight days in total: the epidemic curve is shown in the Figure.

Of the 28 cases, 16 were hospital staff (five of whom were male): 13 were healthcare professionals (nine doctors and four nurses) and three were members of the technical staff (responsible for cleaning and serving food). In addition, 10 of the 28 cases were inpatients (eight of whom were male) and the remaining two cases were symptomatic patients' relatives who had stayed overnight in the ward.

The attack rate among staff members and inpatients was $31 \%$ ( 16 of 51 ) and $16 \%$ (10 of 61 ), respectively (Table 1).

Staff and patients had similar patterns of symptoms (Table 2). Interestingly, nine of the ten affected

\section{TABLE 1}

Attack rate in hospital inpatients and employees, gastroenteritis outbreak due to norovirus infection, Athens, Greece, 9-16 April 2011 ( $\mathrm{n}=26)$

\begin{tabular}{|l|c|c|}
\hline Type of person affected & Number & Attack rate (\%) \\
\hline Inpatients $(n=61)$ & 10 & 16 \\
\hline Employees $(n=51)$ & 16 & 31 \\
\hline Doctors $(n=32)$ & 9 & 28 \\
\hline Nurses $(n=13)$ & 4 & 31 \\
\hline Technical staff $(n=6)$ & 3 & 50 \\
\hline
\end{tabular}

inpatients were immunocompromised. Nevertheless, the illness was mild, with no substantial clinical deterioration.

\section{Laboratory investigation}

Faecal sampling started on 11 April 2011. Two specimens from each inpatient with diarrhoea, except for the index case - a total of 16 samples - were examined in the hospital's microbiological laboratory for Shigella, Campylobacter, Salmonella, Escherichia coli 0157, as well as for Clostridium difficile toxin and the parasite Giardia lamblia, according to standard procedures. None of the samples were positive.

We then tested five consecutive samples, each from different inpatients, for norovirus, using an enzyme immunoassay (RIDA QUICK Norovirus Test, R-Biopharm, Germany) for genogroup I and II. Results were available within 24 hours. For financial reasons, we could not test the samples for all viruses that could be possible causes of the outbreak. We chose to look for norovirus, as this is considered to be a major cause of epidemic viral gastroenteritis and the most common cause of

\section{TABLE 2}

Symptoms of affected hospital inpatients and employees, gastroenteritis outbreak due to norovirus infection, Athens, Greece, 9-16 April $2011(\mathrm{n}=26)$

\begin{tabular}{|l|c|c|}
\hline Symptom & $\begin{array}{c}\text { Number of } \\
\text { affected } \\
\text { inpatients } \\
(\mathrm{n}=10)\end{array}$ & $\begin{array}{c}\text { Number of } \\
\text { affected } \\
\text { employees }^{\mathrm{a}} \\
(\mathrm{n}=16)\end{array}$ \\
\hline Diarrhoea & 9 & 10 \\
\hline Vomiting & 3 & 10 \\
\hline Nausea & 6 & 8 \\
\hline Abdominal pain & 3 & 10 \\
\hline Fever & $38.4 \pm 17.3$ & $32.8 \pm 11.7$ \\
\hline $\begin{array}{l}\text { Mean duration of symptoms, } \\
\text { in hours } \pm \text { Standard deviation }\end{array}$ & & \\
\hline
\end{tabular}

a Unless otherwise indicated.

\section{FIGURE}

Cases of gastroenteritis due to norovirus infection by date of symptom onset, Athens, Greece, 9-16 April 2011 ( $\mathrm{n}=28$ )

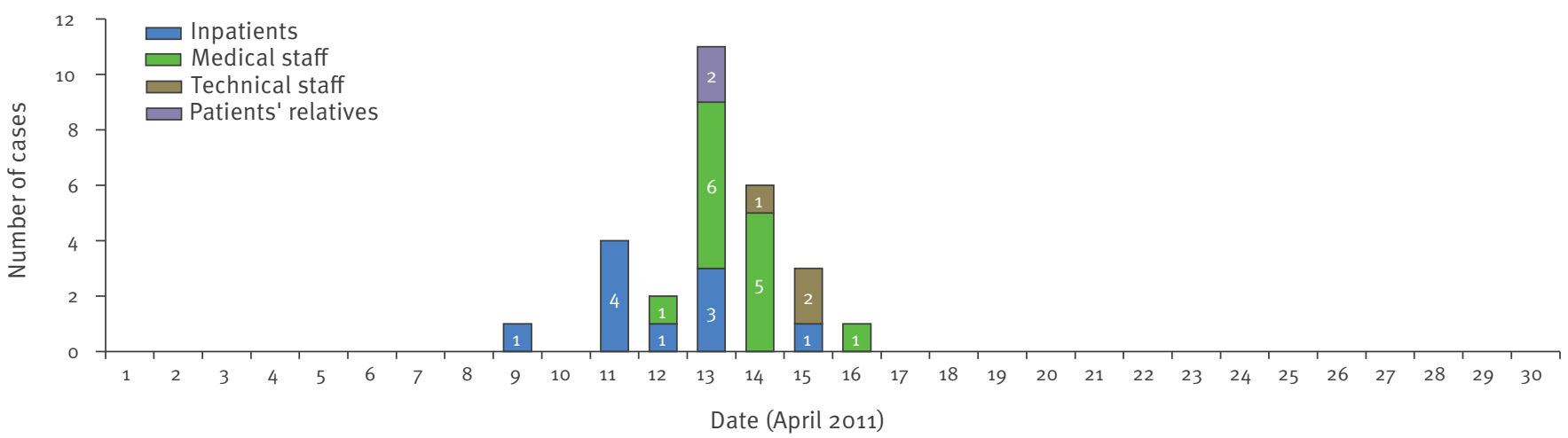


all forms of gastroenteritis in adults worldwide [10]. Norovirus was detected in all five samples.

Similarly, financial constraints did not allow all inpatients to be tested for norovirus and no further typing of the virus could be carried out.

Contaminated food or water was not suspected during the outbreak as no other accumulated cases of acute gastroenteritis were identified concurrently in any other hospital ward; therefore no environmental sampling was carried out.

\section{Infection control measures}

The Hellenic Center for Disease Control and Prevention was notified early, on 13 April, four days after the start of the outbreak. Measures such as enhanced hand hygiene and cleaning with an appropriate disinfectant (1:50 dilution of sodium hypochlorite) of equipment, surfaces and rooms, as well as regular airing of premises were implemented on the same day. In addition, all symptomatic inpatients were isolated by keeping them in three consecutive four-bed rooms. They were allowed to use only designated toilets and bathrooms of the ward that were not used by unaffected individuals. The affected staff were told not to go work for at least three days, until they were no longer symptomatic, according to the standard policy of the hospital. Visits by friends and relatives to affected patients were not allowed. No new admissions to the ward were allowed in order to avoid spreading of the virus. An infection control nurse made daily rounds throughout the hospital to look for new cases and to monitor compliance with infection control measures. No other cases of acute gastroenteritis were reported in any of the other hospital wards.

\section{Discussion}

In this outbreak, the shape of the epidemic curve and the clustering of cases among inpatients and staff suggested that person-to-person transmission was the most likely mode of spread of the causative agent. The source that contaminated the index case was not identified, but given the dates of the appearance of cases, we consider that the virus was probably introduced by a single person and then it spread rapidly in the ward.

Interestingly, a higher attack rate was noted among staff compared with that among inpatients, although the difference was not statistically significant. This is in contrast to previous observations in hospital outbreaks of norovirus infection, which have shown a higher total number of cases, with higher attack rates among the inpatients compared with staff and more prolonged epidemic curve $[11,12]$. A possible explanation is that the infection control measures in the outbreak described in this report were implemented early, but the staff of the ward did not follow the precaution measures meticulously.
Early recognition of the outbreak and prompt implementation of effective infection control measures, including staffing restrictions and ward closure, was successful in containing the spread of the infection to just one ward and limiting the outbreak to a few days' duration. Although the higher attack rate among the staff probably implies that staff did not adhere strictly to infection control precautions, we hope that this outbreak has led to increased awareness of the importance of hand hygiene among hospital personnel.

The majority of the affected inpatients were immunocompromised. Although there is limited experience of norovirus infection in such individuals, recent studies have shown that in such hosts, noroviruses may be shed for prolonged periods of time and the patients may experience severe and life-threatening symptoms $[13,14]$. Although the outbreak described in our report was characterised by mild clinical manifestations, a more aggressive infection in such a setting could lead to severe morbidity, or even fatalities, if not dealt with early.

In conclusion, we report the first documented gastroenteritis outbreak due to norovirus in a Greek hospital: obviously such outbreaks should always be reported in the country. Successful control of the outbreak underlines the importance of the early detection of the causative agent and early and aggressive implementation of efficient control measures. This report underscores the possible role of medical staff in the propagation of outbreaks in healthcare settings if appropriate precaution measures are not taken.

\section{Acknowledgements}

S.P.G. is supported by the Amphiarion Foundation of Chemotherapeutic Studies, Athens, Greece, and N.V.S. and S.P.G. are partly supported by the Special Account for Research Funds (ELKE) of the National and Kapodistrian University of Athens, Greece.

\section{References}

1. Said MA, Perl TM, Sears CL. Healthcare epidemiology: gastrointestinal flu: norovirus in health care and long-term care facilities. Clin Infect Dis. 2008;47(9):1202-8.

2. Simon A, Schildgen O, Maria Eis-Hübinger A, Hasan C, Bode U, Buderus $S$, et al. Norovirus outbreak in a pediatric oncology unit. Scand J Gastroenterol. 2006;41(6):693-9.

3. Grima A, Gatt A, Zahra G, Gambin A. Outbreak of norovirus infection in a nursing home for the elderly in Malta, NovemberDecember 2008. Euro Surveill 2009; 14(4):pii=19103. Available from: http://www.eurosurveillance.org/ViewArticle. aspx?Articleld $=19103$

4. Sharp TW, Thornton SA, Wallace MR, Defraites RF, Sanchez JL, Batchelor RA, et al. Diarrheal disease among military personnel during Operation Restore Hope, Somalia, 1992-1993. Am J Trop Med Hyg. 1995;52(2):188-93.

5. Centers for Disease Control and Prevention (CDC). Norovirus outbreak in an elementary school--District of Columbia, February 2007. MMWR Morb Mortal Wkly Rep. 2008;56(51-52):1340-3.

6. Wikswo ME, Cortes J, Hall AJ, Vaughan G, Howard C, Gregoricus $\mathrm{N}$, et al. Disease transmission and passenger behaviors during a high morbidity norovirus outbreak on a cruise ship, January 2009. Clin Infect Dis. 2011;52(9):1116-22. 
7. Jelastopulu E, Merekoulias G, Alexopoulos EC. Underreporting of communicable diseases in the prefecture of Achaia,

western Greece, 1999-2004 - missed opportunities for

early intervention. Euro Surveill. 2010;15(21): pii=19579.

Available from: http://www.eurosurveillance.org/ViewArticle. aspx?Articleld=19579

8. Jelastopulu E, Alexopoulos EC, Venieri D, Tsiros G, Komninou $\mathrm{G}$, Constantinidis TC, et al. Substantial underreporting of tuberculosis in West Greece: implications for local and national surveillance. Euro Surveill. 2009;14(11):pii=19152. Available from: http://www.eurosurveillance.org/ViewArticle. aspx?Articleld $=19152$

9. Papadopoulos VP, Vlachos O, Isidoriou E, Kasmeridis C, Pappa Z, Goutzouvelidis A, et al. A gastroenteritis outbreak due to norovirus infection in Xanthi, northern Greece: management and public health consequences. J Gastrointestin Liver Dis. 2006;15(1):27-30.

10. Glass RI, Parashar UD, Estes MK. Norovirus gastroenteritis. N Engl J Med. 2009; 361(18):1776-85.

11. Lynn S, Toop J, Hanger C, Millar N. Norovirus outbreaks in a hospital setting the role of infection control. N Z Med J. 2004;117(1189):U771.

12. Stevenson P, McCann R, Duthie R, Glew E, Ganguli L. A hospital outbreak due to Norwalk virus. J Hosp Infect. 1994;26(4):261-72.

13. Sukhrie FH, Siebenga JJ, Beersma MF, Koopmans M. Chronic shedders as reservoir for nosocomial transmission of norovirus. J Clin Microbiol. 2010;48(11):4303-5.

14. Koo HL, DuPont HL. Noroviruses as a potential cause of protracted and lethal disease in immunocompromised patients. Clin Infect Dis. 2009; 49(7):1069-71. 